\title{
European action for victims of medical accidents
}

The European organisation to represent victims of medical accidents took another step forward at a meeting held at the Royal Institute of Public Health in London this year. For this meeting representatives were invited from Austria, Denmark, France, Germany, Great Britain, Holland, Norway, Spain, Sweden and Switzerland.

The guest speaker was Professor Ian Kennedy, professor of medical law at Kings College, London.

$\mathrm{He}$ outlined the aims of any scheme to achieve justice for victims of medical accidents which at least contains three topics. First, to look after victims financially and provide explanations and an apology. Second, to hold a specific health professional liable, providing a deterrent and set out a standard for the future. Third, to device strategies to avoid future accidents.

He went on to say that to deal with accidents a new initiative would be required and tinkering with the present situation would not suffice. There should be legislation for the next century. As far as holding Health professionals to account was concerned, this should be done on a pan-European basis with inspection as well as peer review. This was a system already adopted in the Netherland.
The Danish speaker emphasized that the number of cases with adverse outcomes, faults or cases were patients are dissatisfied with the physicians' conduct are considerable, but in actual fact only a minority of those patients launched a complain. Then dealing with complains, one has to realize, that a law can only be evaluated fairly if one takes due regard to the law as to how it is practiced. In Denmark there have been, too, as a matter of fact, events where the Minister of Health has set aside taking any initiatives, for example, when facing a rather high number of questionable surgical procedures, as well as, in connection with two cases as to how ensure physicians from being mobbed or removed, after they had openly counselled victims of medical accidents.

The French speaker described the almost impossible burden of proof that plaintiffs had to discharge in claiming compensation, i.e. the fault had to be a professional misdemeanor of exceptional seriousness.

The German speaker referred to the particular problem where often patients who tried to allege malpractice were found by doctors to be psychiatrically disturbed and echoed the views of all those present that it was the structural deficiencies in health care provision that had to be addressed. The Swedish speaker underlined that even in Sweden, where there is a system on "no fault" compensation the position for victims of medical accidents and the attitude of doctors towards them is far from satisfactory.

The need for a European net-work was spelled out by the representatives from a number of countries. It was summing up how similar the problems for victims were throughout Europe, i.e. the lack of information, the lack of accountability and the enormous difficulties in getting redress.

The delegates found it of importance to establishing a net-work the European Society for Victims of Medical Accident - with more aims. First, to disseminate information among national organisations and interested individuals. Second, to initiate and encourage research on a European basis as well as on an individual national basis. Third, to inform the politicians and the public of the position for victims of medical accidents.

\section{Address for correspondence}

Erling Segest

Godthåbsvej 85

DK-2000 Frederiksberg/Denmark 